length. It was clear from an inspection of those most recently killed, that they had been killed by some animal for food. The flesh of all had at least been partly devoured, but it was observed that not a carapace nor a plastron was broken. The reptiles had been killed, apparently, by some sharp-beaked bird, by thrusting its beak between the joints of the reptile's armor, so to speak. The loon is clearly competent to do this, but loons are seldom seen in this locality. Moreover these birds would hardly drag their prey so far inland to devour it, as was observed to be the case with many of the turtles. The blue heron is more abundant here than the loon, but still not abundant enough to be credited with so much destructive work on animals so large. I have never suspected him, either, of being a turtle-eater. The only other birds competent to do the work and sufficiently numerous and intelligent to be suspected, are crows. Several flocks of these were hovering about the locality, and though we were not able to approach the wary birds close enough to observe them feeding, our suspicions fell upon them. Has any reader of Science observed crows killing turtles? If so, is this a well established habit of the bird or is it one which has been recently acquired?

Chicago, Ill., 2421 Dearborn Street, June 14.

EDSON S. BASTIN.

\section{The Aurora.}

DR. VeEDER's reply of June 2nd, is so objectionable on account of the positive way in which he closes his part of the argument (believing, as I do, that his facts are in fault) leaving it to be believed that at "no point throughout the research has there appeared to be even the slightest 'chance' for an alternative hypothesis," that I am once more tempted to reply. Let me, before passing on, emphasize the fact that we are not discussing the question of " magnetic storms" and sun-spots. I believe there is only one astronomer and physicist of any eminence who disbelieves in this association, so that as far as discussion of the question is concerned, we may consider it as practically closed; but, even if I held the contrary opinion with the majority, so long as an opponent of such eminence held out, I should consider it inadvisable to be as positive as Dr. Veeder in his last letter, on the subject of the aurora, where, I believe, I am not alone in supposing there is reason to doubt a connection between this display and areas of disturbance on the eastern limb of the sun. I have raised some well-known objections to this theory, and, as a rule. have been met by Dr. Veeder with generalities (Science, April 7, 28, May 19 and June 2); it is unnecessary to mention them again bere, so that I shall content myself with dis. cussing this last contribution, which leaves me in such an uncomfortable position, apparently.

The whole base and superstructure of this theory is erected upon a solar period of rotation of " $27 \frac{1}{4}$ days," and to quote from a letter which I have received from Dr. Veeder, dated March 16, 1892 , the addition of " a few hours difference in the length of the period introduces a drift into the tables that becomes every. where apparent." Surely this is a suspicious degree of perfection in the theory, as no one knows what the solar period of rotation is: such pericds as have been determined from sun-spots (the only possible method so far) give values between 25 and $27 \frac{1}{2}$ days, depending on the solar latitude of the spot; yet, the addition of a "few hours" can introduce a "drift which becomes everywhere apparent," when $2 \frac{1}{2}$ days is left out of the tabulating without apparent effect, for, it is evident, that in considering the effects of the return to the eastern limb of a sun-spot or area of disturbance, that it is not a fixed rotational period that should be used, but the one belonging to the latitude of the spot under discussion.

This year auroras were visible here on the following days of the year: the $5 \mathrm{th}, 6 \mathrm{th}, 8 \mathrm{th}, 21 \mathrm{st}, 35 \mathrm{th}, 36 \mathrm{th}, 44 \mathrm{th}, 45 \mathrm{th}, 46 \mathrm{th}$, 47th, 104th, 109th, 127th, 128th, 130th, 144th, 145th, 160th, 164th, 165 th and $166 \mathrm{th}$. If auroras are caused by a disturbed solar area at the eastern limb, we should find, by adding the interval adopted by Dr. Veeder of $27 \frac{1}{4}$ days to any of the above days, the probable date of the returning display. What do we find in fact? That, of the 52 periods obtained by adding this interval in succes- sion to the above days, up to the present date, there were only 10 of the days so determined on which displays took place; that is, 20 per cent of successes as against 80 per cent of failures. In illustration of the above, the aurora of the 5th day should have reappeared on the $32 \frac{1}{4}, 59 \frac{1}{2}, 86 \frac{3}{4}, 114$ and $141 \frac{1}{4}$; from the days of auroras given above, it will be seen it appeared on none of the required dates; nor did that of the $6 \mathrm{th}$; that of the 8 th reappeared twice out of five solar periods; the 21st, once out of five; the 35th, once out of four, and so on.

One more objection, previously overlooked, before passing on. I am of opinion (no one can be certain, failing the necessary observations), that there is practically no instance in which aurora displays are not taking place in one hemisphere or other of the earth; a large proportion should be observed co-incident with any" other class of recurrent phenomena, and think it possible that "chance," which Dr. Veeder avoids the discussion of, is really an important element in our discussion, as I shall now endeavor to prove this by his own admissions.

In a letter to me, dated May 4, 1892, he says: "The year 1879 , selected for printing as an illustration of the results seen throughout the entire table, is one of profound minimum at which times solar disturbances are well separated from each other and the relation comes out distinctly although for the construction of such a table one year is just as good as another." (italics are mine.) This is a perfectly sound conclusion, and by it alone might this theory stand or fall if " chance" is not, or is, as important as I maintain. On May 13th, Dr. Veeder writes: (This table of comparison between the phenomena being now printed) "It [1879] being a year of minimum the relation does not come out so strongly as when disturbances were more numerous. In the next year (1880) the numbers would be much larger and the relation in every way more distinct.

So far, then, Dr. Veeder has been about equally positive on both sides of this question, both of which opinions are apparently obtained from the observations he is in possession of, leaving the possibility open (it is his suggestion) that we are very far from "a realizing sense, that it is facts and not a personality against which" we "are contending."

Might I again suggest the advisability of setting a limit on the term "eastern limb," adhering rigidly to it throughout the investigation, not admitting too much of the suppositional when sunspots fail at the required period by the substitution of "faculae," and seeing how far the element of "chance" enters into this question by showing a continuous series of comparisons through a semi-period, at least, of solar activity.

Quebec, May 17.

$$
\text { W. A. AsHe. }
$$

\section{Scientific Words in the Century Dictionary.}

ALthough one of the most useful books published, the Century Dictionary is, of course, not faultless. The mention of a mistake in a recent issue of The Critic reminded me also of the following:-

According to the latest edition of Foster's "Physiology," saliva "in a healthy subject is alkaline, especially when the secretion is abundant. When the saliva is scanty, or when the subject suffers from dsspepsia, the reaction of the mouth may be acid." According to the Century Dictionary, the saliva "is a colorless ropy liquid which normally has an acid reaction."

The word "griffe," which is commonly used in Louisiana, is defined by the Century Dictionary as a " a mulatto-especially a mulatto woman." I have copied in a note-book from a lecture delivered in New Orleans by Hon. Charles Gayarré, the historian of Louisiana and authority on such matters, the following:-

"In Creole America there is a very mixed population. Even in very early times there were these distinctions: European, or fresh white immigrant; Creole, or pure white American of European parentage; the aboriginal Indian; the griffe, or cross between Indian and negro; the mestizo, or mixed white and Indian; the mulatto, etc., etc." These may not be the exact words of the speaker, since I may have misunderstood or copied it wrongly, but I think the same statement may be found in one of his works. Griffe, no doubt, is from the Spanish grifos, meaning frizzled 
hair. This is a peculiarity of many of the crosses between Indian and African. I need but mention the Cafusos, who, according to Tyler, "are remarkable for their hair, which rises in a curly mass, forming a natural periwig. which obliges the wearers to stoop low in passing through their hut doors."

The word playa is not mentioned in the Century Dictionary, although, according to the Popular Science Monthly, vol xxii., p. 381 , it " has been adupted by geologists as a generic term, under which the various desiccated lake-basins of the West may be grouped."

Although the oese, or platinum-needle or loop, is the most important tool of the bacteriologist, both of these words have been omitted. The word oese is, of course, German, but is now much used in English books.

The common names, and of ten the scientific names, of wellknown plants have been omitted. The Amorphophallus titanum, a vegetable wonder of the Arum family, discorered in Sumatra in 1878 by Beccari, is not mentioned under its generic or common East Indian name of Krubut, although both of these appear under Rufflesia, the generic name of a remarkable plant which grows with it.

The word noctilucent is defined in the Century Dictionary, but the word noctilucence, a term sometimes applied to the light emitted by the Noctiluca, is omitted, although phosphorescence is the more common, but perhaps less accurate, term.

Many of the definitions are inaccurate and unsatisfactory. From the following definition of Cartb, one would conclude that they are all of a "native race" and that none are living in the Caribbean Islands at the present time: "One of a native race inbabiting certain portions of Central America and the north of South America, and formerly also the Caribbean Islands." According to the latest Handbook, in British Honduras, there are 2,200 Caribs who, "'although to all appearance of true African origin, being a black and woolly-headed people, are a mixed race of the aboriginal Caribs, with a large percentage of African blood." A few true Red Caribs and some Black Caribs still live in the Windward Islands. The true Caribs are not natives of Central America. They inhabited the northern part of South America and the Caribbean Islands, and, according to Dr. Brinton, their original home was south of the Amazon. JOHN. GIFFORD.

Swarthmore College, Pa.

\section{A Peculiar Occurrence of Beeswax.}

In Science for June 16, 1893, Mr. George C. Merrill, of the U. S. National Museum, has a request for information under the above heading concerning some beeswax forwarded to bim from Portland, Oregon. He describes it as having all the elements and characteristics of beeswax, but says, "such it would have unhesitatingly been pronounced but for certain stated conditions relating to its mode of occurrence."

He says it occurs in the sand along the beach, at quite a depth in places, and in a fragment of sandstone, etc., and further says: "Tradition has it that many hundred years ago a foreign vessel (some say a Chinese junk) laden with wax was wrecked off this coast. This at first thought seems plausible, but aside from the difficulty of accounting for the presence in these waters and at that date of a ressel loaded with wax, it seens scarcely credible that the material could have been brought in a single cargo in such quantities nor buried so deeply orer so large an area."

The first difficulty Mr. Merrill seems to encounter is the presence of a vessel of that supposed nation on our coast at so early a date. This should give him no difficulty whatever, for Hon. Horace Davis, of California, in an article before the American Antiquarian Society, April, 1892; Charles Walcott Brooks before the California Academy of Sciences, March 1, 1875, and Professor George Davidson, of the U. S. Coast Survey, for thirty years or more last past, have all been calling attention to the hundreds of known wrecks of Japanese (not Chinese) junks cast on the American shores, from Behring Sea to Peru, by the "Kuro Shiwo," or black stream of Japan

In both the articles mentioned above you will find an account of the "beeswax junk" and so much information concerning it that Mr. Merrill's doubts will be dissipated; if not, Professor Davidson, in the "Coast Pilot of California, Oregon and Washington Territory," 1869 , describes this very junk and the very beeswax in question.

Mr. Merrill's informant, however, seems to have fallen into an error as to the quantity and locality of this wax; for no such quantities were ever found as those mentioned in Science; in fact, the story is this: At some recent-but prehistoric-time a Japanese junk loaded with beeswax was thrown ashore at or near Clatsop beach, Oregon, and the cargo was scattered along the sands and buried therein, where it is found even today in small quantities and that is all.

Mr. Merrill's letter to Science is published, he sass, "in the hope of gaining more information on the subject," and I will be fully repaid if through the instrumentality of this note he shall have obtained that information.

Many Japanese wrecks have been thrown ashore on our coast, of which we have authentic information, all the proof of which has largely been collected by the eminent gentlemen quoted above.

Tacoma, Washington, June 26. JAMES WICKERSHAM.

\section{Color Perception: A Correction.}

I HASTEN to send this note of correction to my paper on "Distance and Color Perception by Infants" in Science, April 28 - an error brought to my attention by a friend. In Tables I. and II. of that article (p. 231) I have taken the proportion of "acceptances" to the entire number of cases (the ratio $\frac{A}{N}$ ) after adding up the simple numbers for each color at all the distances. It is evident that the resulting percentages are $w$ rong as representing. comparative results for the different colors, since there are not an equal number of cases for each same color at different distances, nor for the different colors at each same distance. The proper method is, of course, to compound the percentages representing the relative attractiveness of each color at each distance. This gives the values $\left(\right.$ for $\frac{A}{N}$ ) in Table I. : Blue, .78; red, .75; white, .78 ; green, .68; brown, .43; and in Table II.: Newspaper, .76; color, .71. This brings white up to the level of blue and red. The same correction should be made for the values $\frac{R}{n}$, but in the result it is immaterial

I wish to add, also, that I do not consider the results relative to the individual colors of much value, since the cases are so tew. The experiments had to be broken off unexpectedly. I published the tables mainly to illustrate the working of the method of experimenting. For this reason $I$ did not enter in my article into side considerations, such as color-brightness, fatigue, etc., which were duly provided for in the experiments themselves. I bope to discuss such points in the fuller treatment of the monograph on the infant's active life which I am preparing.

Princeton, N.J., June 30.

J. MaRK BaLdwin.

\section{Birds that Sing in the Night.}

I have read with a great deal of interest the notes under this head as they hare appeared in Science from time to time. While some species have been mentioned that I have not heard, there are also some not mentioned which are night singers in central Iowa, where I have spent many years studying the birds in their rarious moods and conditions.

The first in point of beauty of execution is the wood-thrush (Turdus mustelinus). Not only does he sing in the night, but his song is given at shorter intervals and more earnestly then than during the day. It is rarely that he sings at high noon, unless the day be dark and wet. Nor does he sing all night long; from midnight until after two, there is only an occasional burst of song or none at all.

Second in point of regularity and persistence is dickcissel (Spiya americana). Not only does he sing at short intervals all 